\title{
Research on the Construction of New Science and Technology Think Tank in China
}

\author{
Sisi $\mathrm{Li}^{1, \mathrm{a},{ }^{*}}$, Shiwei Zhu ${ }^{1, \mathrm{~b}}$, Junfeng $\mathrm{Yu}^{1, \mathrm{c}}$, Mingjun Zhang ${ }^{1, \mathrm{~d}}$, Cuiqin $\mathrm{Liu}^{1, \mathrm{e}}$ and \\ Beibei $X u^{1, f}$
}
${ }^{1}$ Information Institute, Qilu University of Technology (Shandong Academic of Sciences), Jinan, Shandong, China

aliss@sdas.org, ’zhusw@sdas.org, cyujf@sdas.org, dzhangmj@sdas.org, eliucq@sdas.org, fxubeib@sdas.org

${ }^{*}$ Corresponding author

\begin{abstract}
Keywords: Science and technology think tank, New think tank with Chinese characteristics, Decision-making consultation, Scientific research institution
\end{abstract}

\begin{abstract}
The think tank is the product of the modern decision-making system, plays an important role in the government decision-making consultation system. It is important to promote the scientific and democratic decision-making. Science and technology think tank is an organic part of the new think tank with Chinese characteristics, the General Office of the Central Committee and the General Office of the State Council pointed out in Opinions on strengthening the construction of new think tanks with Chinese characteristics, building high level scientific and technological think tank has an important significance for the researchers and Research and Consulting Institutions. With investigation and research, this paper sorts out the significance of building science and technology think tanks, analyzes the main problems existing in the construction of science and technology think tanks and puts forward relevant countermeasures.
\end{abstract}

\section{Introduction}

On the third Plenary Session of the 18th CPC Central Committee, the Party adopted the decision of "the Central Committee of the Communist Party of China on several major issues concerning comprehensively deepening reform" in November 2013. The decision clearly put forward that strengthen the construction of a new type of think tank with Chinese characteristics and establish and improve the decision-making consultation system. This is the direction for the construction of our new scientific and technological think tank. "National high-end think tank construction pilot work program" was approved and identified 25 pilot high-end think tank in November 2015, this marks a new think-tank construction with Chinese characteristics started. General Secretary Xi Jinping has made it clear that technology think-tank should study the major issues related to the overall situation from the perspective of the impact of science and technology and the role, follow the rules of science and technology, forward-looking thinking about the development trend of world science and technology and make recommendations, to carry out scientific assessment, predict the forecast, so as to play a constructive role in national macroeconomic decision-making. Science and technology think tank as an important part of the new think tank with Chinese characteristics. It has a distinctive technical characteristics, plays a pivotal role in the leap-forward development of science and technology and the planning and implementation of national science and technology strategy.

Previously, we translate "Think Tank" as "Think Stock", the definition has been interpreted as: think stock is a stable and relatively independent policy research institution, researchers interdisciplinary research on a wide range of policy issues using scientific research methods, provide information consulting on policy issues closely related to government, business and the public. Think stock is also interpreted as: think tank is an independent organization engaged in a multidisciplinary study that seeks to influence public policy. Up to now, academics have a more 
unified understanding of the think tank. The organization of the think tank is policy research institutions, the work content is policy research, the clients are policy makers and the public, the goal is to influence public policy. It has the characteristics of independence, nonprofit, multidisciplinary and multi-disciplinary, multi-type etc. With the expand of concept, connotation and denotation of think tank, the number of think tank is also growing. According to incomplete statistics, there are nearly 5000 different types of think tanks in the world.

Although the development of the think tank has made a great breakthrough, but the definition of science and technology think tank has not yet reached a consensus. The technology think tank has the general features of think tank and technological characteristics. The content of the think tank has knowledge and technology intensive; Research and analysis are interdisciplinary, reflect the intersection of natural, social and humanistic sciences; The researchers are mainly natural scientists and also involve human scientists and social scientists. Wang Guixia said that science and technology think tank is social organization use professional knowledge and scientific tools, to carry out public policy and decision-making research and consulting, to solve their own development issues or technology-based economic and social decision-making problems. Tong Zhengrong said that science and technology think tank subject to policy of science and technology as the object of study, subject to influence the choice of social science and technology policy as the goal, provide scientific decision-making for the development of science and technology, economic and social development, with good scientific and technological research team organizations, including various research institutes, research centers, foundations, institutions of higher learning, associations, societies, forums, databases, websites, magazines etc.

\section{The Significance of the Construction of science and technology think tank}

\subsection{The construction of science and technology think tank is conducive to improving the scientific and democratic decision-making}

Today's society is a totally profound and rapidly changing society, the scientific and democratic decision-making of government is one of the important tasks in the construction of socialist democratic politics. In this environment, the decision-making of the Party and the government in the important areas and the key aspects of reform is facing a more complex environment and more arduous tasks, so scientific decision-making, democratic decision-making is even more important. It can be seen that strengthening the construction of science and technology think tank, promote the participation of science and technology experts and scholars in public decision-making, focusing on global and long-term strategic issues and the urgency of different phases. In the decision-making of Party and the government, especially the decision-making of science and technology policy, to express their views, suggestions and calls, let science and technology think tank set up a bridge between people and policymakers. Undoubtedly, it is the support and guarantee of expanding the orderly political participation of citizens, promoting deliberative democracy and improving the scientific decision-making.

\subsection{The construction of science and technology think tank is internal requirement of comprehensively deepen reform}

Under the background of economic globalization, political polarization and cultural diversity, science and technology think tank has become one of the important part of national soft power. It plays a more and more important role in the social and economic development, prosperity and stability of the country or region. China is in the period of comprehensive deepening of the reform and the conversion period of economic growth, the environment of the world, domestic situation and the situation of the Party have changed profoundly. In the process of promoting comprehensively deepen reform, in the face of increasingly complex international and domestic situation, changes in economic and social environment, Party committees and governments on the various levels of contemporary China, the demand for decision-making in various fields is even 
more urgent. Whether it is to guide the reform, or in matters related to economic and social development and scientific and technological related issues, Party committees and governments at all levels are in great need of science and technology think tank to effectively solve the development problems, provide intellectual support and theoretical support in a timely manner.

\subsection{The construction of science and technology think tank is the inevitable choice of scientific and technological workers}

Scientific and technological workers with high level of scientific and cultural, professional knowledge, careful observation, logical thinking rigorous, position objective, with the decision-making advice to carry out the natural advantages and suggestions and strong will. Strengthen the construction of science and technology think tank is good to overcome the phenomenon of single work, theoretical retreat and interested with the topic of interest. What's more, science and technology think tank is conducive to gathered together the various disciplines, all aspects of the front of the scientific and technological workers. Science and technology think tank is good for integrate cross-industry, interdisciplinary, cross-regional intellectual resources together, select topics according to social needs, make the individual wisdom of science and technology workers rose to organized collective wisdom, promote the Party committee and the government scientific decision-making, promote the development of science and technology and personnel training, to provide strategic reserve, policy reserve and talent reserve.

\section{Prominent Problems in the Construction of Science and Technology Think Tanks in China}

\subsection{Mechanism is imperfect}

Firstly, reflected in the lack of institutional constraints. Party committees and governments at various levels, especially when making important decisions, tend to seek advice from relevant experts in the decision-making process. However, the solicitation of the opinion of the think tank expert is not mandatory, sometimes ignoring the solicitation of opinions. Or after the comments, didn't pay enough attention on the opinions. Secondly, the information communication channels are not smooth. Information is the basis of government decision-making and the basis of the source of opinion of the think tank. The improper information channel will lead to the understanding of think tank experts to the Party committees and government is not sufficient, which will lead to the actual research and demand disjointed with the phenomenon, thus can not play the real role of the think tank. Finally, the role of experts has not been fully exploited. The functional departments responsible for the preparatory work for many major issues such as investigation and study, comprehensive planning, project demonstration, advice, etc. The result is that the interests of departments tend to consciously or unconsciously affect the decision-making and implementation of major issues, which led to the think tank experts are difficult to have a positive impact on decision-making.

\subsection{The conversion rate of the research results is low}

First of all, the quality of the research results is not high. The research results of the science and technology think tank are mostly in terms of papers, works, etc., but they are not pay enough attention to some real problems. So lack of comprehensive, profound and systematic, forward-looking opinion is difficult to have a positive impact of decisions. Secondly, the propaganda of research results is not enough. In the promotion of the results, the current practice is mostly only focus on government agencies and their officials to promote their research results, and the public to carry out the dissemination of intellectual results propaganda is not high, leading to many research results are not known to the outside world. Finally, the incentive mechanism is not perfect. Lack of research results evaluation system, has not yet formed to encourage the pursuit of research quality of the value orientation, have negative effects on the enthusiasm of think tank 
researchers.

\subsection{Lack of integration research}

First reflected in the decentralization of various departments. Think tank groups are generally distributed in various departments and various research areas, such as research institutes, Party and government departments, enterprises, universities and so on. Independent operation between these various departments, less communication and did not form a consolidation force. Coupled with the lack of unified planning and organizational leadership, leading to the inability to concentrate resources, fragmented, low-level research, sealing study, repeated study and other phenomena. First reflected in lack of communication and cooperation. The project management department and the think tank organization closed to each other, the resources cannot be shared, the lack of effective coordination, their respective research, interaction and cooperation mechanism has not yet formed, to a certain extent, caused the duplication of resources and research funds unreasonable distribution. Finally, the development of basic resources is weak. Many think tank structure of talents is not reasonable, in particular, domain experts and high-level researchers is inadequate, the construction of information technology is seriously lagging behind. Lack of relevant accumulation of research has seriously restricted the benign development of the think tanks.

\subsection{Talent training \&accumulation mechanism has not been established}

First reflected in the absence of the introduction of market mechanisms. Because of the lack of economic leverage, the sources of expert teams in think tanks are single and low-level, and lack of well-known and high-level experts at home and abroad. Second reflected in the training mechanism of talent has not yet established. For the think tank team, there is a lack of systematic and effective training. This has led to the lack of research ability of think tank team researchers, and there are obstacles to communication with experts, what's more, the research ability need further improve. Finally, there is no corresponding talent gathering mechanism. As the gathering mechanism of talent is not perfect, the think tank has not yet become a platform for Talent Gathering. Think tank talent team should not only include experts and researchers, but also should include some relevant personnel such as college students, retired officials and professors, senior business experts and other personnel.

\section{The focus of the science and technology think tank in China}

\subsection{Broaden the construction path of science and technology think tank}

First of all, more academic exchanges should be carried out. The academic exchange activities will be conducive to the transformation of intellectual achievements into science and technology think tank achievements, centre on the major issues of economic and social development and the "13th Five-Year" industry positioning, the organization to carry out the corresponding activities of cross regional, interdisciplinary, cross sector, such as the international science and technology exchange and cooperation activities, Academic Salon, science and Technology Forum etc.. Secondly, the construction of sci-tech periodicals should be strengthened. Around the needs of innovation driven development, efforts will be made to build a number of international academic journals with high quality exchange platform. In organizing academic exchange activities, we should pay attention to improving the organizational level, establish a corresponding incentive mechanism, and pay more attention to the exchange and use of academic achievements. In the construction of journals, should build digital journal platform to support the construction of fine journals, enhance the influence and competitiveness of China's science and technology journals. Finally, we should encourage the research of scientific and technological subjects. Encourage and organize scientific research personnel, science and technology workers to invest in research projects, provide a strong theoretical support for the decision-making advisory work. 


\subsection{Forming a talent pool for the construction of high-level think tank}

To build a small center, large peripheral technology think tank, set up full-time\&part-time team of scientific and technological experts, cultivate a high level, strong quality, discipline and expert team of experts, is essential for the construction of high-level science and technology think tank. First of all, we should strengthen the construction of high-end expert team, and form a team supported by high-end experts, which will provide guidance for the decision-making of science and technology think tank. Secondly, we should strengthen the team building of think tank base. Innovation, practice, the focus of the construction of the think tank should focus of grassroots. Should jointly establish science and technology think tank base, relying on the base, gathered all kinds of experts and talents. Finally, we should strengthen the team construction of the investigation site. Based on the survey of science and technology workers, establish a stable and special investigation team. Strengthen the national and provincial scientific and technological workers survey site construction and management, to promote the construction of municipal survey sites, and constantly expand the coverage of the province's investigation site, and constantly expand the scientific and technological community gathering platform.

\subsection{Endeavor to become decision-making "think tank" of the Party committees and the governments}

Science and technology think tank as a bridge between the Party and the government of science and technology workers, always represents the first productive forces of science and technology and talent resources, should be united to unite the broad masses of science and technology workers, provide decision-making advice and other services for the Party and the government. We should actively promote the advantages of science and technology intelligence into government departments scientific decision-making, extensive contacts with the community of high-level experts, the formation of advantage in comprehensively and accurately grasp the technology, advanced rules, develop innovation strategy, reflect talent status etc..

\subsection{Improve the use mechanism of science and technology think tank}

First of all, we should improve the service sharing mechanism. Using "Internet plus" mode, improve the operation mechanism of science and technology, integrated information service platform, online reporting, online project and project evaluation, expert technology consulting achievements of scientific and technological achievements together, push, science and technology workers survey etc.. Build information platform to enable researchers to achieve online and offline interaction, establish data sharing mechanism, effectively serve the majority of researchers. Secondly, we should improve the mechanism of achievement transformation. Hold the forum or annual meeting of science and technology, provide a good platform for researchers' academic exchanges, achievements display and suggestions. Researchers keep close ties with the Party committees and governments, broaden the channels for researchers' political consultation and actively participate in the process of democratic decision-making. Finally, incentive evaluation mechanism should be improved. Think tank groups are encouraged to carry out research activities such as research and soft science research, and develop valuable and innovative and operational research reports. For the excellent research results should be properly funded, regularly carry out the recommendations of researchers and research report selection activities. To construct the evaluation mechanism properly, combined with practice, and choose the best results of science and technology think tank recommended to the relevant decision-making departments, broaden the application achievements into channels, play the greatest degree of science and technology think tank as the "think tank" role.

\section{Acknowledgement}

Financial supports from the Key Science and Technology Program of Shandong Province (2016GGX101018) and the Key Science and Technology Program of Shandong Province 
(2017GGX10118) and the staged achievements of Shandong Academy of Sciences Think Tank Project 'Technical foresight and innovation assessment of Shandong Province' are gratefully acknowledged.

\section{References}

[1] Zhiping Yang, Huang Siyu. Study of news from the news professionalism consumerism [J]. Journal of lanzhou, 2014 (9) : 202-208.

[2] GuPeng Yuliu Tao. Since 1949, our country sports news report the change of perspective [J]. Journal of sport, 2011 (2) : 41-49.

[3] Dickson P. Think Tanks [M]. New York: Atheneum, 1971.

[4] James S. The Idea Brokers: the Impact of Think Tanks on British Government [J]. Public Administration, 1993, 71(4): 491-506.

[5] Sun Zhiru, Zhang Zhiqiang. Analysis of the organization and development of scientific think tanks [J]. Information Work, 2010, (2): 34-37.

[6] Sun Zhiru, Zhang Zhiqiang. Historical evolution and development of the think tank [J]. Information Journal, 2011, 30 (1): 37-41.

[7] WANG Gui-xia, WAN Jin-bo, ZHAO Lan-xiang.Study on the Interface Relationship between Science and Technology Think Tank and Its Impact Object [J]. China Science and Technology Forum, 2014, 12: 50-55.

[8] Tong Zhengrong, Zhang Liangqiang. The Development of Science and Technology Think Tank in Taiwan and Its Implications for the Construction of Science and Technology in Mainland China [J]. Science and Technology Progress and Countermeasures, 2015, 32 (15): 32-36. 